\title{
Electrochemical interactions of industrially important platinum-containing minerals
}

\author{
M.K.G. Vermaak ${ }^{a}$, J.D. Miller ${ }^{b}$ and J. Lee ${ }^{b}$ \\ ${ }^{a}$ Department of Materials Science and Metallurgical Engineering, University of \\ Pretoria, Pretoria 0002, South Africa \\ ${ }^{b}$ Department of Metallurgical Engineering, University of Utah, Salt Lake City, United \\ States
}

\section{Abstract}

$\mathrm{Pt}-\mathrm{Te}_{2}$ and $\mathrm{Pt}-\mathrm{Bi}-\mathrm{Te}$ are two important platinum-carrying minerals typically found in altered platinum reserves. Mineralogical studies indicate the $\mathrm{Pt}-\mathrm{Pd}-\mathrm{Bi}-\mathrm{Te}$ class to react poorly on the flotation stimuli and indications are that these minerals are slow floaters. This paper investigates the fundamental interactions of potassium ethyl xanthate with these minerals by employing electrochemically controlled contact angle measurements, FT-IR spectroscopy and voltammetry. The electrochemical investigations revealed that $\mathrm{Pt}-\mathrm{Te}_{2}$ is more noble than $\mathrm{Pt}-\mathrm{Bi}-\mathrm{Te}$ at potentials lower than $300 \mathrm{mV}$ (SHE) in sodium tetraborate buffer solution and the reduction peak observed during the return sweep of $\mathrm{Pt}-\mathrm{Bi}-\mathrm{Te}$ is mainly associated with the reduction of bismuth oxidation products. Both the minerals show increased anodic currents when polarised at $0.3 \mathrm{~V}$ (SHE) in a $0.05 \mathrm{M}$ $\mathrm{Na}_{2} \mathrm{~B}_{4} \mathrm{O}_{7}$ solution containing $1 \times 10^{-3} \mathrm{M}$ potassium ethyl xanthate. According to the results of the rest potential measurements, formation of dixanthogen should be thermodynamically favourable and the very high rest potentials are attributed to the catalytic effect of platinum on the oxygen reduction reaction. The formation of dixanthogen on both the minerals was confirmed by ex situ FT-IR spectroscopy. Contact angle measurements revealed the surface of $\mathrm{Pt}-\mathrm{Bi}-\mathrm{Te}$ to be hydrophobic in nature whereas small contact angles were realized on $\mathrm{Pt}-\mathrm{Te}_{2}$. Surface roughness of the mineral could be responsible for these small contact angles. 


\section{Article Outline}

1. Introduction

2. Experimental

2.1. PGM synthesis

2.2. Electrochemical investigations

2.3. Contact angle measurements

2.4. FT-IR spectroscopy

3. Results and discussion

3.1. Oxidation in tetraborate

3.1.1. Interactions with xanthate

3.1.2. Contact angle measurements

4. Conclusions

References

\section{Introduction}

In contrast to traditional platinum processing routes, recent advances in beneficiation technologies are also directed towards the recovery of platinum-group elements (PGEs) from altered deposits. Such altered deposits include the Platreef, the Great Dyke reserve in Zimbabwe and oxidised UG-2 and Merensky reefs. Open cast mining methods are employed in most instances because of the shallow nature of these reefs. The economic advantages of employing this mining method are counteracted by difficulties encountered during processing, resulting in lower PGE recoveries than for unaltered Merensky and UG-2 ores. These platinum sources are usually characterised by the following: oxidised sulfides, altered gangue minerals (for example, serpentine in case of Platreef), a large portion of PGMs belonging to the classes Pd-Pt-Bi-Te (Great Dyke and Platreef ores), Pt-Pd-S-As, and PGE-alloy (for example PtFe in oxidised UG-2), poorer association with base metal sulfides, a large portion of PGMs associated with gangue minerals (regrinding is required to prevent excessive losses to the tailings), a large portion of PGMs liberated during milling and significant losses of liberated PGMs to tailings. 
The occurrence of liberated PGMs in the tailings streams of the concentrators necessitates research on the oxidation and collector interaction of these minerals. There are practical indications that the recovery of the $\mathrm{Pd}-\mathrm{Pt}-\mathrm{Bi}-\mathrm{Te}$ class from these reserves (Platreef and Great Dyke) is poor. (Vermaak et al., 2004) and (Vermaak et al., 2005) performed an investigation on synthetic $\mathrm{Pd}-\mathrm{Bi}-\mathrm{Te}$ employing voltammetry, impedance measurements, Raman spectroscopy and microflotation. These studies indicated a very strong interaction of ethyl xanthate with $\mathrm{Pd}-\mathrm{Bi}-\mathrm{Te}$ resulting in the formation of a hydrophobic surface state. Dixanthogen and a metal xanthate species were identified on the surface by performing in situ Raman spectroscopy. The small size of the liberated PGMs, less than $10 \mu \mathrm{m}$, and interactions with the sulphide particles could contribute to the poor flotation response of these particles.

Similar to that of $\mathrm{Pd}$, the $\mathrm{Pd}-\mathrm{Pt}-\mathrm{Bi}-\mathrm{Te}$ class is a major $\mathrm{Pt}$ carrier and recent sharp increases in the platinum price have resulted in increased efforts to understand the flotation behaviour of this class. With more and more attention being given on the recovery of PGEs from altered platinum reserves, this work investigates the fundamental interactions of the most important platinum-carrying minerals typically found in altered PGE ores (i.e. Pt-Bi-Te and $\mathrm{Pt}-\mathrm{Te}_{2}$ ).

\section{Experimental}

\subsection{PGM synthesis}

The synthesis procedure of the synthetic crystals $\left(\mathrm{Pt}-\mathrm{Bi}-\mathrm{Te}\right.$ and $\mathrm{Pt}-\mathrm{Te}_{2}$ ) is similar to that of $\mathrm{Pd}-\mathrm{Bi}-\mathrm{Te}$, which is given elsewhere ([Vermaak et al., 2004] and [Vermaak et al., 2005]). Instead of applying a heat treatment lasting several days at $480^{\circ} \mathrm{C}$ as used by Vermaak et al. (2005), a fully homogeneous microstructure was only obtained in this study by employing the heat treatment at $480{ }^{\circ} \mathrm{C}$ for up to 60 days.

A back-scattered electron imaging and XRD analysis performed on the synthetic crystals, provided no evidence of phases other than the intended $\mathrm{Pt}-\mathrm{Bi}-\mathrm{Te}$, and $\mathrm{Pt}-\mathrm{Te}_{2}$. 


\subsection{Electrochemical investigations}

A conventional electrochemical cell with a three-electrode system, consisting of a working electrode (synthetic mineral), platinum counter electrode and reference electrode, was used. The PGM crystals were mounted in resin and electrical contact was achieved between the contactor shaft and the mineral by employing a spring. Potentials were measured against a $\mathrm{KCl}$-saturated $\mathrm{Ag} / \mathrm{AgCl}$ reference electrode, which has a potential of $+0.20 \mathrm{~V}$ on the standard hydrogen electrode scale. For all the electrochemical measurements, a potentiostat (Model PCI4/750) and electrochemical software (PHE200 Physical Electrochemistry Software) from Gamry Instrument Inc. were employed. Sodium tetraborate at a concentration of $0.05 \mathrm{M} \mathrm{Na}_{2} \mathrm{~B}_{4} \mathrm{O}_{7}$ was used to buffer the solution at $\mathrm{pH}$ 9.3. Electrolytes were prepared using analytical grade reagents and distilled water with a final resistivity of $18 \mathrm{M} \Omega \cdot \mathrm{cm}$. Prior to each experiment, the solution was deaerated for $2 \mathrm{~h}$ with argon gas (99.999\%). When the electrochemical measurement commenced, the gas disperser was raised above the solution level to keep a slight positive pressure within the cell. Cyclic voltammograms were recorded at a scan rate of 1 and $20 \mathrm{mV} / \mathrm{s}$ starting from the most negative potentials going positively to the upper potential and then reversed. Polarisation diagrams were recorded at a scan rate of $1 \mathrm{mV} / \mathrm{s}$. Electrochemical measurements were conducted after the open-circuit potential had stabilised. The solution was replaced between experimental runs to avoid contamination. Purified collectors were used in all the experiments. The surface of the PGM electrode was renewed between every experimental run by grinding with P-4000 grade silicon carbide under a constant stream of de-oxygenated distilled water.

\subsection{Contact angle measurements}

The electrodes were sequentially dry ground with 600 and 4000 grit silicon carbide paper prior to each experiment. The influence of dry and wet polishing for $\mathrm{Pt}-\mathrm{Bi}-\mathrm{Te}$ electrode was examined. The above-mentioned polishing treatment gave reproducible results. Supporting electrolytes of $0.05 \mathrm{M}$ sodium tetraborate was used which provided a buffered solution of $\mathrm{pH} 9.3$. 
Regular de-ionized water (DI) was used in all of the experimental work. Ultra pure deionized water (UPDI) $(18 \mathrm{M} \Omega \cdot \mathrm{cm})$ was used to study the difference between regular DI and UPDI water for the contact angle measurements. All other chemicals used were of analytical reagent grade quality. Prior to each experiment, the solution was de-aerated for $2 \mathrm{~h}$ with ultra high purity nitrogen. A conventional three-electrode system was employed with an EG\&G Princeton Applied Research Potentiostat/Galvanostat (Model 173) to control electrode potential. The contact angle measurement (captive bubble with mineral electrode facing down) procedure involved stepping the potential to the required value for $5 \mathrm{~min}$. The contact angle was measured directly after polarisation was terminated (opencircuit conditions). A nitrogen bubble was introduced to the surface and contact angles were measured on both sides of the bubble. A number of bubbles were placed as quickly as possible on the surface from which contact angles were measured. A standard deviation and $95 \%$ confidence interval were determined of the contact angles measured for the different runs. Latex gloves were worn throughout the experiments to avoid the contamination of the mineral surfaces.

\subsection{FT-IR spectroscopy}

Complementing electrochemical investigations with studies using FT-IR reflection spectroscopy have provided valuable information on the nature of the surface species. The FT-IR spectra of surfaces of the electrodes were recorded with a Perkin-Elmer GX 2000 FT-IR Spectrometer, adapted with Perkin-Elmer Auto Image Microscope System which is critically aligned with it. The influence of the atmospheric water was always subtracted. The samples were analysed in reflectance mode under the Auto Image FTIR microscope employing a liquid-nitrogen-cooled MCT detector. The spectral resolution was at least $4 \mathrm{~cm}^{-1}$ for all the measurements. After polarisation the samples were immediately transferred to the FT-IR spectrometer for ex situ measurements.

\section{Results and discussion}

\subsection{Oxidation in tetraborate}

The variations of the current as a function of potential, obtained by changing the potential linearly with time between -0.6 and $0.3 \mathrm{~V}$ (SHE) at a scan rate of $20 \mathrm{mV} / \mathrm{s}$, for Pt- $\mathrm{Te}_{2}$ 
and Pt-Bi-Te shown in Fig. 1 and Fig. 2. These current-potential curves were measured in triplicate. Anodic currents (on both of the minerals) are evident in the region $>200 \mathrm{mV}$ in the absence of the collector and probably reflect oxidation of the mineral surface. Oxidation of $\mathrm{Pt}-\mathrm{Bi}-\mathrm{Te}$ commences at a lower potential (see also Fig. 4). The higher peak current density of $\mathrm{Pt}-\mathrm{Bi}-\mathrm{Te}$ reflects the more reactive nature of this mineral at potentials lower than $300 \mathrm{mV}$. The reverse scan of cyclic voltammogram of Pt-Bi-Te shows a reduction peak at $-250 \mathrm{mV}$, which is not present in the case of the $\mathrm{Pt}-\mathrm{Te}_{2}$ electrode. The cyclovoltammogram of pure Bi buffered at $\mathrm{pH} 9.2$ is shown in Fig. 3. The reduction peak recorded on the pure bismuth corresponds well with the reduction peak obtained on Pt$\mathrm{Bi}-\mathrm{Te}$ in tetraborate. This reduction peak appears to be related to the reduction of the bismuth oxidation products (possibly formed by reaction 1) formed during the positivegoing scan; oxidation of $\mathrm{Bi}$ is possible in this potential range as shown by the equilibrium potential (Pourbaix, 1974):

$$
\begin{aligned}
& 2 \mathrm{Bi}+3 \mathrm{H}_{2} \mathrm{O}=\mathrm{Bi}_{2} \mathrm{O}_{5}+6 \mathrm{H}^{+}+6 \mathrm{e}^{-} \\
& E^{0}=0.371-0.0591 \mathrm{pH}
\end{aligned}
$$

Hence $E^{0}$ at $\mathrm{pH} 9.3$ is $-0.179 \mathrm{~V}$, which lies between the potentials at which the anodic current increases sharply for the positive-going scan on $\mathrm{Bi}$, and where the cathodic peak is observed on the negative-going scan.

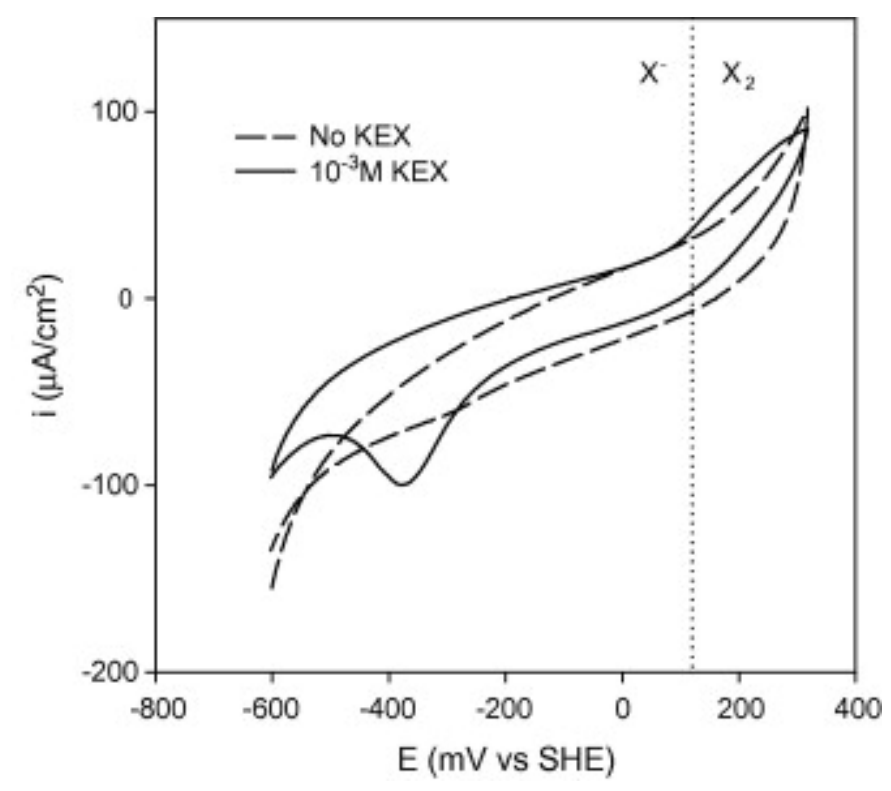


Fig. 1. Current-potential curves for $\mathrm{Pt}-\mathrm{Te}_{2}$ electrodes in a $0.05 \mathrm{M} \mathrm{Na}_{2} \mathrm{~B}_{4} \mathrm{O}_{7}$ solution at $25^{\circ} \mathrm{C}$ in the absence and presence of xanthate $\left(10^{-3} \mathrm{M} \mathrm{KEX}\right)$. Starting potential of $-0.6 \mathrm{~V}$ (SHE) and positive initial sweep direction. Potential sweep carried out at $20 \mathrm{mV} / \mathrm{s}$.

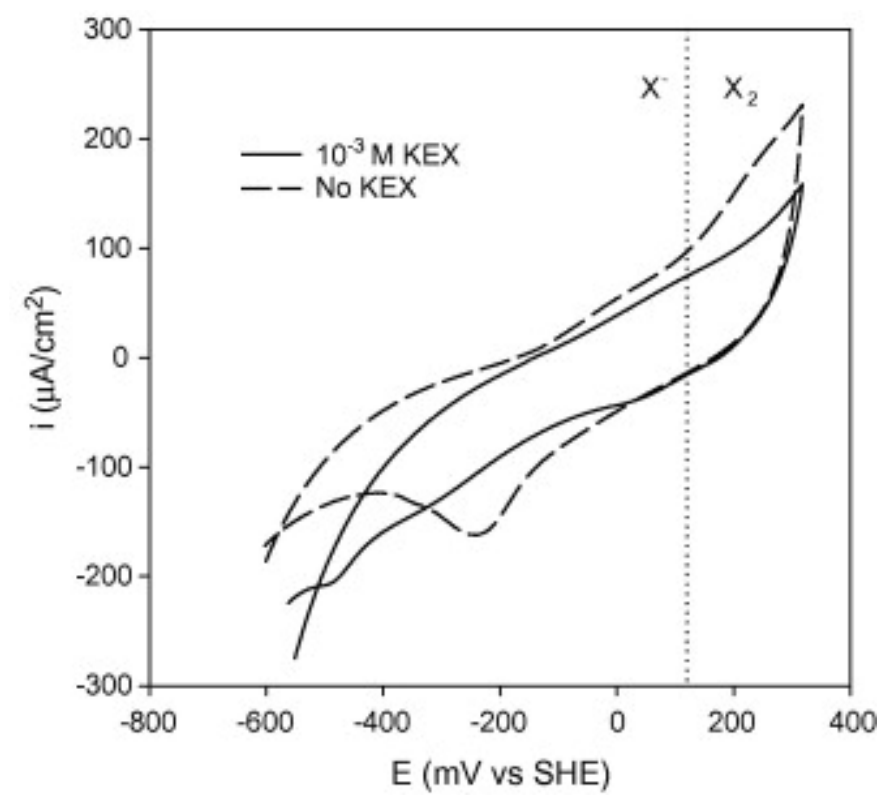

Fig. 2. Current-potential curves for Pt-Bi-Te electrodes in a $0.05 \mathrm{M} \mathrm{Na}_{2} \mathrm{~B}_{4} \mathrm{O}_{7}$ solution at $25^{\circ} \mathrm{C}$ in the absence and presence of $\operatorname{KEX}\left(10^{-3} \mathrm{M}\right)$. Starting potential of $-0.6 \mathrm{~V}$ (SHE) and positive initial sweep direction. Potential sweep carried out at $20 \mathrm{mV} / \mathrm{s}$.

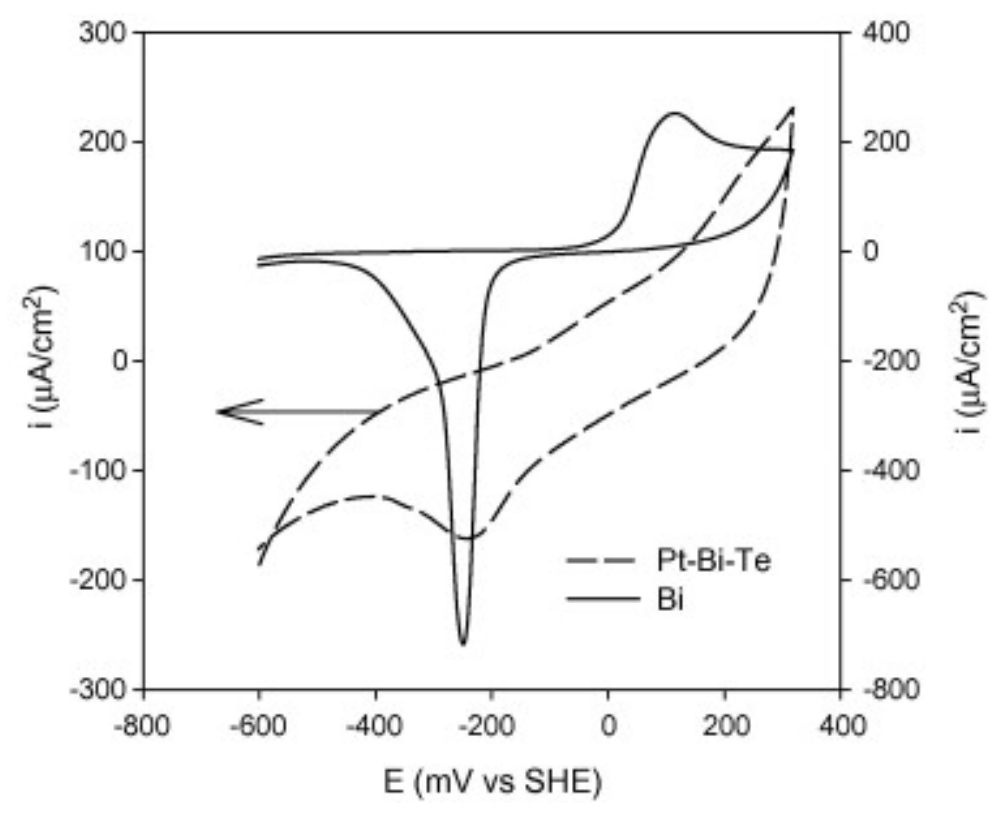

Fig. 3. Current-potential curves for Pt-Bi-Te and Bi electrodes in a $0.05 \mathrm{M} \mathrm{Na}_{2} \mathrm{~B}_{4} \mathrm{O}_{7}$ solution at $25^{\circ} \mathrm{C}$. Starting potential of $-0.6 \mathrm{~V}$ (SHE) and positive initial sweep direction. Potential sweep carried out at $20 \mathrm{mV} / \mathrm{s}$. 
Elvy et al. (1996) investigated the incongruent oxidation of $\mathrm{Pd}-\mathrm{Bi}-\mathrm{Te}$ in air and indicated the reactivity of the minerals decreased in the following order: $\mathrm{PdBi}>\mathrm{PdTeBi}>\mathrm{PdTe}$. This is the same order as the reactivities of Bi, Te and Pd in the pure form. Fig. 4 shows the anodic polarisation (scans performed at $1 \mathrm{mV} / \mathrm{s}$ ) of $\mathrm{Pt}-\mathrm{Bi}-\mathrm{Te}, \mathrm{Pt}-\mathrm{Te}_{2}, \mathrm{Bi}$ and $\mathrm{Te}$ in de-oxygenated solutions containing tetraborate as $\mathrm{pH}$ buffer. The figure underlines the fact the $\mathrm{Bi}$ is more reactive than $\mathrm{Te}$ for potentials $<300 \mathrm{mV}$. The polarisation diagrams of $\mathrm{Pt}-\mathrm{Bi}-\mathrm{Te}$ and $\mathrm{Pt}-\mathrm{Te}_{2}$ shown in Fig. 3 indicate the slightly more noble nature of the later for potentials $<300 \mathrm{mV}$. However above $300 \mathrm{mV} \mathrm{Pt}-\mathrm{Te}_{2}$ shows increased anodic behaviour which can be related to the oxidation of the tellurium (possibly by reaction 2 forming a soluble product, instead of the solid oxide which is expected for oxidation of Bi). In contrast to the prominent oxidation peak shown in Fig. 1, a cathodic peak related to the reduction of the oxidised products is absent or associated with much smaller currents. The absence of this peak is mainly associated with the soluble or non-protective nature (loosely bound product layer) of the oxidation products formed. The kinetics of the oxidation in solution is not very well understood, but if oxidation proceeds at a high enough rate, oxidation could impact negatively on the flotation process (Pourbaix, 1974).

$$
\mathrm{Te}+3 \mathrm{H}_{2} \mathrm{O}=\mathrm{TeO}_{3}^{2-}+6 \mathrm{H}^{2}+4 \mathrm{e}^{-}
$$

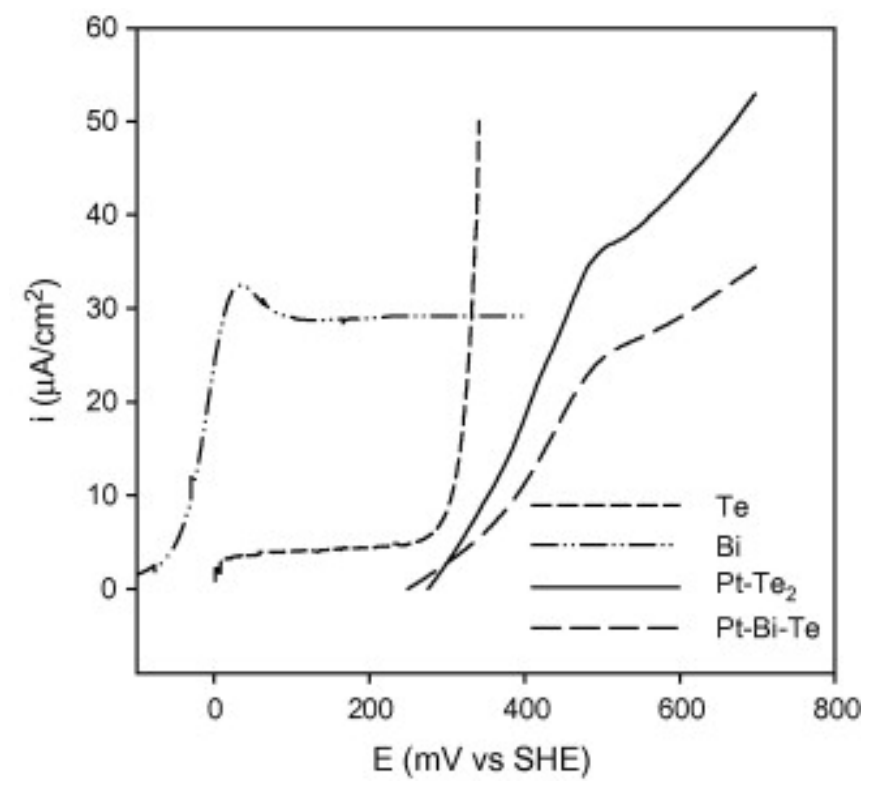

Fig. 4. Anodic behaviour of the selected PGMs and metals in a de-oxygenated solution containing $0.05 \mathrm{M} \mathrm{Na}_{2} \mathrm{~B}_{4} \mathrm{O}_{7}$. Potential sweep carried out at $1 \mathrm{mV} / \mathrm{s}$. 


\subsubsection{Interactions with xanthate}

The cyclovoltammograms of $\mathrm{Pt}-\mathrm{Te}_{2}$ and $\mathrm{Pt}-\mathrm{Bi}-\mathrm{Te}$ obtained in the presence of xanthate $\left(10^{-3} \mathrm{M}\right)$ buffered at $\mathrm{pH} 9.2$ are also shown, respectively, in Fig. 1 and Fig. 2. Pt-Te shows a strong anodic behaviour at potentials $>120 \mathrm{mV}$ in the presence of xanthate; this potential corresponds well with the reversible potential for the xanthate-dixanthogen couple (Gardner and Woods, 1974). A strong cathodic peak appears on the reverse scan. Fig. 2 shows a smaller rate of increase in the anodic activity of Pt-Bi-Te compared to Pt$\mathrm{Te}_{2}$ (the difference is more prominent in the polarisation diagram shown in Fig. 5) when polarised at $300 \mathrm{mV}$ (SHE) and as a result no prominent reduction peak is evident on the return sweep. However, the presence of xanthate inhibits the electrochemical reactions taking place in tetraborate indicating a strong interaction with the xanthate. Fig. 5 shows the linear voltammetry results of $\mathrm{Pt}-\mathrm{Bi}-\mathrm{Te}$ and $\mathrm{Pt}-\mathrm{Te}_{2}$ obtained by changing the potential linearly with time between 0.15 and $0.4 \mathrm{~V}$ (SHE) at a scan rate of $1 \mathrm{mV} / \mathrm{s}$ in the absence and resence of xanthate. The increased anodic activity in the presence of xanthate is evident for both the minerals.

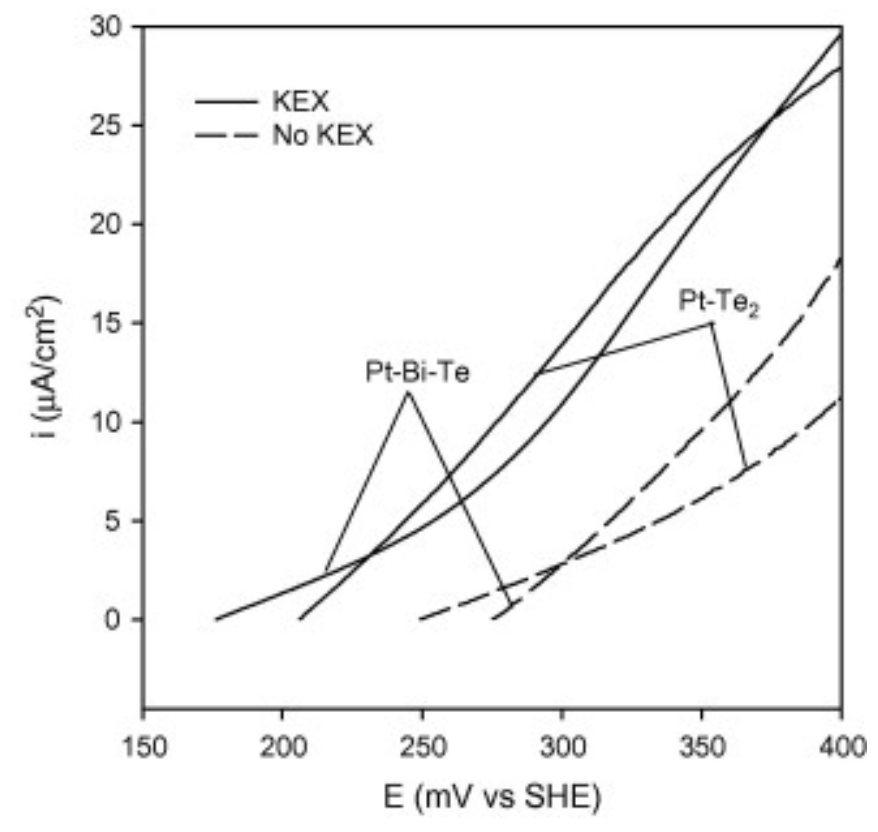

Fig. 5. The influence of KEX on the anodic polarisation behaviour of Pt-Bi-Te and Pt$\mathrm{Te}_{2}$. Current-potential curves constructed at a scan rate of $1 \mathrm{mV} / \mathrm{s}$ in a $0.05 \mathrm{M} \mathrm{Na}_{2} \mathrm{~B}_{4} \mathrm{O}_{7}$ solution at $25^{\circ} \mathrm{C}$ in the absence (- - - ) and presence (-) of potassium ethyl xanthate. Vermaak et al. (2004) reported the presence of xanthate and dixanthogen on the surface of Pd-Bi-Te when polarised at $0.3 \mathrm{~V}$ (SHE) in the presence of KEX (concentration of 
$\left.10^{-3} \mathrm{M}\right)$. In order for dixanthogen to form as reaction product the mixed potential obtained across the mineral interface must exceed that of the equilibrium reversible potential for the xanthate-dixanthogen couple. The reversible potential for the xanthatedixanthogen couple at a collector concentration of $10^{-3} \mathrm{M}$ is $0.121 \mathrm{~V}$ (SHE) (Gardner and Woods, 1974). The effectiveness of the cathodic reactions on the substrate affects the attainable mixed potential. The effective reduction of oxygen on the surface would result in higher mixed potential being obtained. Vermaak et al. (2004) showed that the true mixed potential for Pd-Bi-Te in an oxygen-saturated solution containing $10^{-3} \mathrm{M} \mathrm{KEX}$ was higher than the equilibrium potential for the xanthate-dixanthogen couple. $\mathrm{Pt}-\mathrm{Bi}-\mathrm{Te}$ is expected to show similar high mixed potential values giving its comparable noble nature. The current-potential curves for $\mathrm{Pt}-\mathrm{Bi}-\mathrm{Te}$ and $\mathrm{Pt}-\mathrm{Te}_{2}$, which are shown, respectively, in Fig. 6 and Fig. 7, were constructed in the same way as described elsewhere (Vermaak et al., 2004). The intersection of the cathodic and anodic polarisation diagram (for $10^{-3} \mathrm{M} \mathrm{KEX}$ ) gives the estimated mixed potential for the system under the prevailing conditions. Rest potential measurements were carried out, to compare this estimate to the actual rest potential measurements. Fig. 8 shows the true rest potential behaviour for $\mathrm{Pt}-\mathrm{Bi}-\mathrm{Te}$ and $\mathrm{Pt}-\mathrm{Te}_{2}$ as a function of time. The procedure employed to measure the rest potentials of the relevant electrodes is given elsewhere (Vermaak et al., 2004).

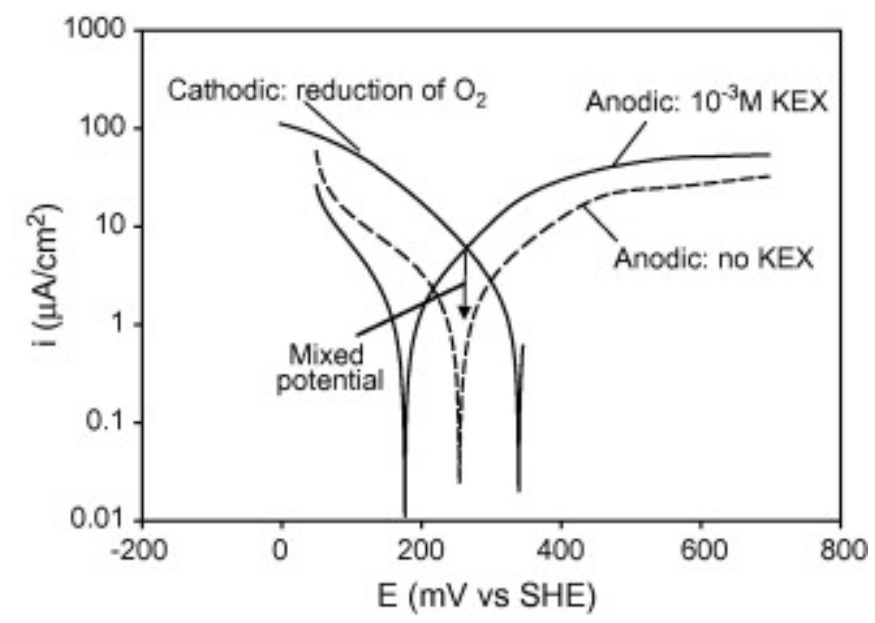

Fig. 6. Current-potential curves for a Pt-Bi-Te electrode in a $0.05 \mathrm{M} \mathrm{Na}_{2} \mathrm{~B}_{4} \mathrm{O}_{7}$ solution in the absence and presence of potassium ethyl xanthate $\left(10^{-3} \mathrm{M}\right)$. The cathodic scan was performed in an oxygenated-borate solution $\left(0.05 \mathrm{M} \mathrm{Na}_{2} \mathrm{~B}_{4} \mathrm{O}_{7}\right)$ at a scan rate of $1 \mathrm{mV} / \mathrm{s}$. 


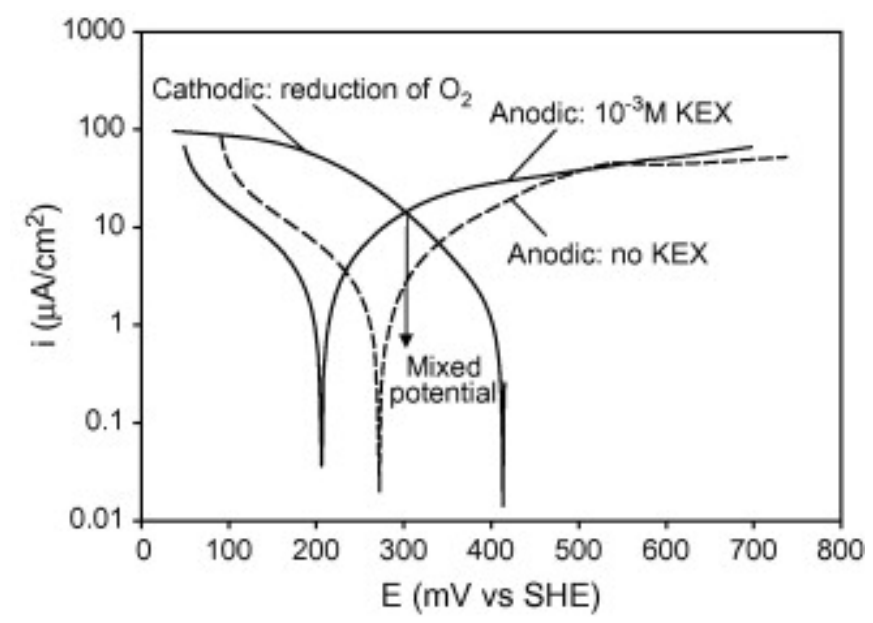

Fig. 7. Current-potential curves for a $\mathrm{Pt}-\mathrm{Te}_{2}$ electrode in a $0.05 \mathrm{M} \mathrm{Na}_{2} \mathrm{~B}_{4} \mathrm{O}_{7}$ solution in the absence and presence of potassium ethyl xanthate $\left(10^{-3} \mathrm{M}\right)$. The cathodic scan was performed in an oxygenated-borate solution $\left(0.05 \mathrm{M} \mathrm{Na}_{2} \mathrm{~B}_{4} \mathrm{O}_{7}\right)$ at a scan rate of $1 \mathrm{mV} / \mathrm{s}$.

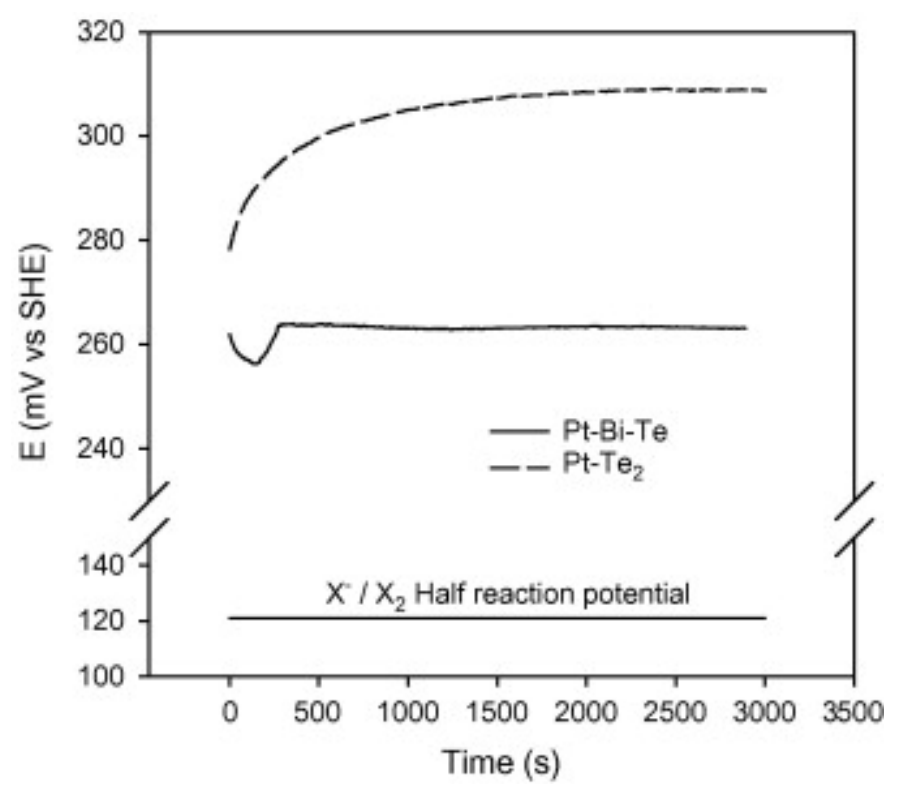

Fig. 8. Mixed potential for $\mathrm{Pt}-\mathrm{Bi}-\mathrm{Te}$ and $\mathrm{Pt}-\mathrm{Te}_{2}$ in an oxygenated solution containing $10^{-3} \mathrm{M} \mathrm{KEX}$, at a $\mathrm{pH}$ value of 9.2. Also indicated in the figure is the equilibrium potential for the xanthate-dixanthogen couple at a collector concentration of $10^{-3} \mathrm{M}$ KEX.

The true mixed potentials (see Fig. 8) compare well with the predicted mixed potentials as determined by the intersection of the individual cathodic and anodic polarisation diagrams. The differences between the predicted and true mixed potentials are usually 
less than $25 \mathrm{mV}$, and the mixed potential values (for both minerals) are greater than the equilibrium potential for the xanthate-dixanthogen couple in the presence of oxygen. The steady-state rest potential value for $\mathrm{Pt}-\mathrm{Te}_{2}$ is $308 \mathrm{mV}$ compared to the $263 \mathrm{mV}$ for PtBi-Te. This clearly indicates that the formation of dixanthogen is possible on freshly prepared surfaces of $\mathrm{Pt}-\mathrm{Bi}-\mathrm{Te}$ and $\mathrm{Pt}-\mathrm{Te}_{2}$. However the rest potential values attained for the Pt-Bismuthotellurides are appreciable higher than those measured on $\mathrm{Pd}-\mathrm{Bi}-\mathrm{Te}$ $(150 \mathrm{mV})$ (Vermaak et al., 2004). This clearly indicates the increased efficiency of the reduction of oxygen on the Pt-containing minerals or slower anodic kinetics.

Ex situ FT-IR spectra from Pt-Bi-Te and Pt-Te 2 electrodes polarised for 10 min at $0.3 \mathrm{~V}$ (SHE) in $0.05 \mathrm{M}$ sodium tetraborate solution containing $1 \times 10^{-3} \mathrm{M}$ potassium ethyl xanthate are shown in Fig. 9. The following FT-IR bands were identified on the Pt-BiTe, as illustrated in Fig. 9: 1026, 1046, 1111, 1244, 1274, 1294 and $1373 \mathrm{~cm}^{-1}$. The FTIR spectra of Pt- $\mathrm{Te}_{2}$ exhibits clear bands at 1025, 1044, 1110, 1242, 1270, 1291 and $1368 \mathrm{~cm}^{-1}$; the small shifts of a maximum of about $4 \mathrm{~cm}^{-1}$ (see the band around $1270 \mathrm{~cm}^{-1}$ in case of $\mathrm{Pt}-\mathrm{Te}_{2}$ ) is approaching the spectral resolution of the instrument. Leppinen et al. (1991) indicated that the characteristic bands of dixanthogen $\left(\mathrm{EX}_{2}\right)$ are: 1270, 1248, 1112, 1044 and $1030 \mathrm{~cm}^{-1}$. Bozkurt et al. (1999) reported the bands at 1242, 1267 and $1022 \mathrm{~cm}^{-1}$ to be characteristic of dixanthogen. For dixanthogen the asymmetrical stretching appears as a strong absorption peak at $\sim 1265 \mathrm{~cm}^{-1}$ while the symmetrical stretching appears as a weak absorption peak at $\sim 1150 \mathrm{~cm}^{-1}$. In the case of the xanthate both the asymmetrical and symmetrical $\mathrm{C}-\mathrm{O}-\mathrm{C}$ stretching absorption peaks are of similar intensities - the symmetrical $\mathrm{C}-\mathrm{O}-\mathrm{C}$ stretching for the xanthate is at $\sim$ $1150 \mathrm{~cm}^{-1}\left(\sim 1150 \mathrm{~cm}^{-1}\right.$ for dixanthogen) and the asymmetrical stretching absorption is at $\sim 1100 \mathrm{~cm}^{-1}\left(\sim 1265 \mathrm{~cm}^{-1}\right.$ for dixanthogen) (Poling, 1976). 


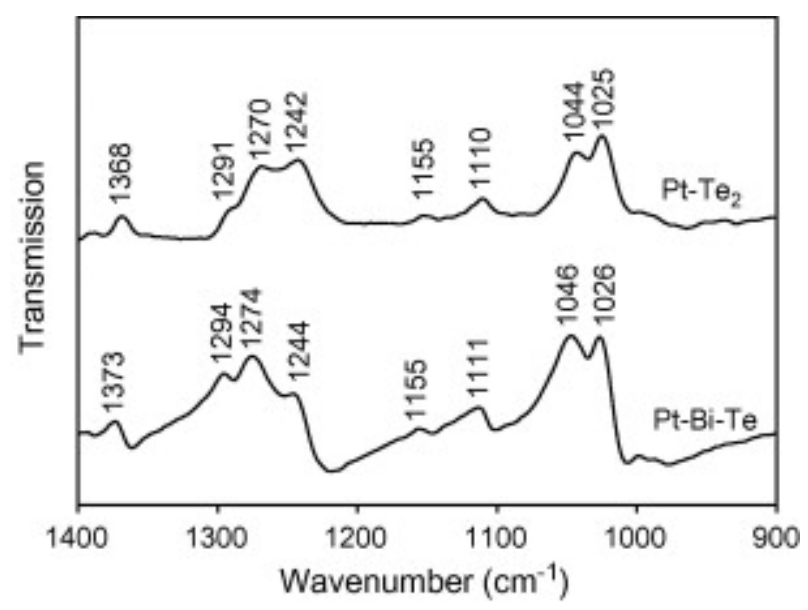

Fig. 9. Ex situ FT-IR spectra of $\mathrm{Pt}-\mathrm{Te}_{2}$ and $\mathrm{Pt}-\mathrm{Bi}-\mathrm{Te}$ electrodes polarised at $0.3 \mathrm{~V}$ (SHE) in $0.05 \mathrm{M} \mathrm{Na}_{2} \mathrm{~B}_{4} \mathrm{O}_{7}$ solution containing $1 \times 10^{-3} \mathrm{M}$ potassium ethyl xanthate for $10 \mathrm{~min}$. Notwithstanding these small shifts in band positions compared to the literature, the FT-IR spectra clearly confirm that dixanthogen is present on the electrode surfaces. The anodic behaviour of the electrodes as shown in Fig. 4 and Fig. 5 hence reflects oxidation of xanthate to dixanthogen. The band at about $1240 \mathrm{~cm}^{-1}$ is characteristic of xanthate; the position of the band depends on the metal ion in the compound (Sundholm and Talonen, 1994). However, no bands could be found of chemisorbed xanthate or metal xanthate on the surface of the mineral; even for short polarisation times $(5 \mathrm{~min})$. The presence of a chemisorbed xanthate layer on these cannot be ruled out - the layer may simply be undetected by FT-IR.

\subsubsection{Contact angle measurements}

Fig. 10 shows the contact angle behaviour of $\mathrm{Pt}-\mathrm{Bi}-\mathrm{Te}$ and $\mathrm{Pt}-\mathrm{Te}_{2}$ electrodes in a $0.05 \mathrm{M}$ $\mathrm{Na}_{2} \mathrm{~B}_{4} \mathrm{O}_{7}$ solution at $25^{\circ} \mathrm{C}$ in the presence of $10^{-3} \mathrm{M} \mathrm{KEX}$ after $300 \mathrm{~s}$ of polarisation at the relevant potential. This figure shows that, in the presence of ethyl xanthate, a zero contact angle was observed on Pt- $\mathrm{Te}_{2}$ at potentials which yielded negligible anodic currents on the voltammograms (for example, $0 \mathrm{mV}$ in Fig. 3). Appreciable contact angles on $\mathrm{Pt}-\mathrm{Bi}-\mathrm{Te}$ (i.e. $30^{\circ}$ ) were present in the potential region (i.e. $<150 \mathrm{mV}$ ) where negligible anodic currents were present - this phenomenon is not expected and is attributed to surface roughness. 


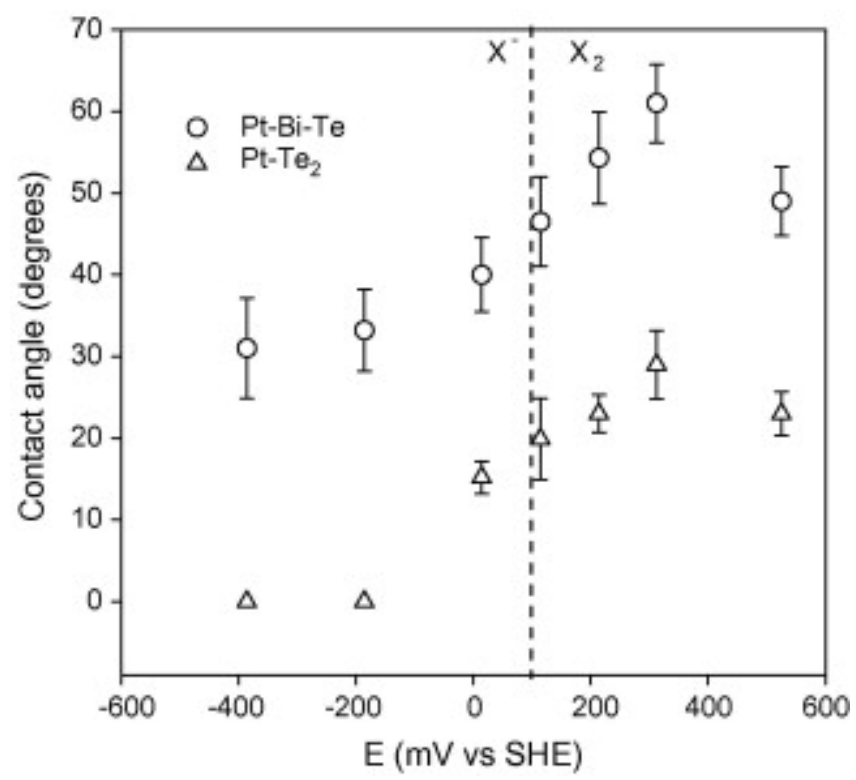

Fig. 10. Contact angles for $\mathrm{Pt}-\mathrm{Bi}-\mathrm{Te}$ and $\mathrm{Pt}-\mathrm{Te}_{2}$ electrode in a $0.05 \mathrm{M} \mathrm{Na}_{2} \mathrm{~B}_{4} \mathrm{O}_{7}$ solution at $25^{\circ} \mathrm{C}$ in the presence of $10^{-3} \mathrm{M} \mathrm{KEX}$ after $300 \mathrm{~s}$ of polarisation at the relevant potential. The equilibrium potential for the oxidation of xanthate to dixanthogen is indicated on the graph, by vertical broken line.

When the potential was increased to more anodic values the contact angle of $\mathrm{Pt}-\mathrm{Te}_{2}$ increased to a maximum of only $29^{\circ}$. In contrast, the contact angle on $\mathrm{Pt}-\mathrm{Bi}-\mathrm{Te}$ reached a maximum of $61^{\circ}$. The maximum angle measured corresponds well with that of $\mathrm{Pd}-\mathrm{Bi}-\mathrm{Te}$ where an angle of $63^{\circ}$ was measured (Vermaak et al., 2004). The contact angle measurements demonstrate that the surface of $\mathrm{Pt}-\mathrm{Bi}-\mathrm{Te}$ is hydrophobic at high potentials and that bismuth seems to be an important constituent in these minerals if a hydrophobic surface state is to be established. The increase in the contact angles during anodic polarisation for both the minerals can probably be attributed to the formation of dixanthogen - however the effect of xanthate cannot be ruled out. In case of the $\mathrm{Pt}-\mathrm{Bi}-\mathrm{Te}$ this hydrophobicity will result in the flotation of the particle if sufficient quantities of the surfactant are present and successful bubble attachment is achieved.

However, the contact angle measurements on $\mathrm{Pt}-\mathrm{Te}_{2}$ indicate poor hydrophobicity at high potentials - maximum angles of only around $29^{\circ}$ were realised. Yan and Hariyasa (1997) indicated the effectiveness of amyl xanthate in the flotation of gold tellurides. To test this 
possibility, contact angle behaviour of $\mathrm{Pt}-\mathrm{Te}_{2}$ and $\mathrm{Pt}-\mathrm{Bi}-\mathrm{Te}$ in the presence of $10^{-3} \mathrm{M}$ potassium amyl xanthate (PAX) was measured (after $300 \mathrm{~s}$ of polarisation at the relevant potential). As Fig. 11 shows, PAX (a thiol with a much longer alkyl chain than KEX) did not improve the surface hydrophobicity of $\mathrm{Pt}-\mathrm{Te}_{2}$ significantly. Despite the strong interaction of xanthate with the $\mathrm{Pt}-\mathrm{Te}_{2}$ surface and the formation of dixanthogen, the reason for the low surface hydrophobicity of $\mathrm{Pt}-\mathrm{Te}_{2}$ is unclear. However the surface roughness of the electrode can have a pinning effect on the advancing contact angle since the surface roughness creates energy barriers which are difficult to overcome. The technique of measuring contact angles is arguably not the ideal measuring technique in this case and other techniques such as microflotation tests would give a better indication of the hydrophobicity of the surface. However the high cost and difficulties encountered producing homogeneous synthetic minerals on a sufficiently large scale are some of the challenges facing microflotation tests. Given the formation of dixanthogen on the surface $\mathrm{Pt}-\mathrm{Te}_{2}$ should therefore be recovered by flotation. It is believed that particle size effects and the presence of sulfides adversely affect the flotation of these minerals - much more research needs to be performed to fully understand the flotation mechanisms of these minerals.

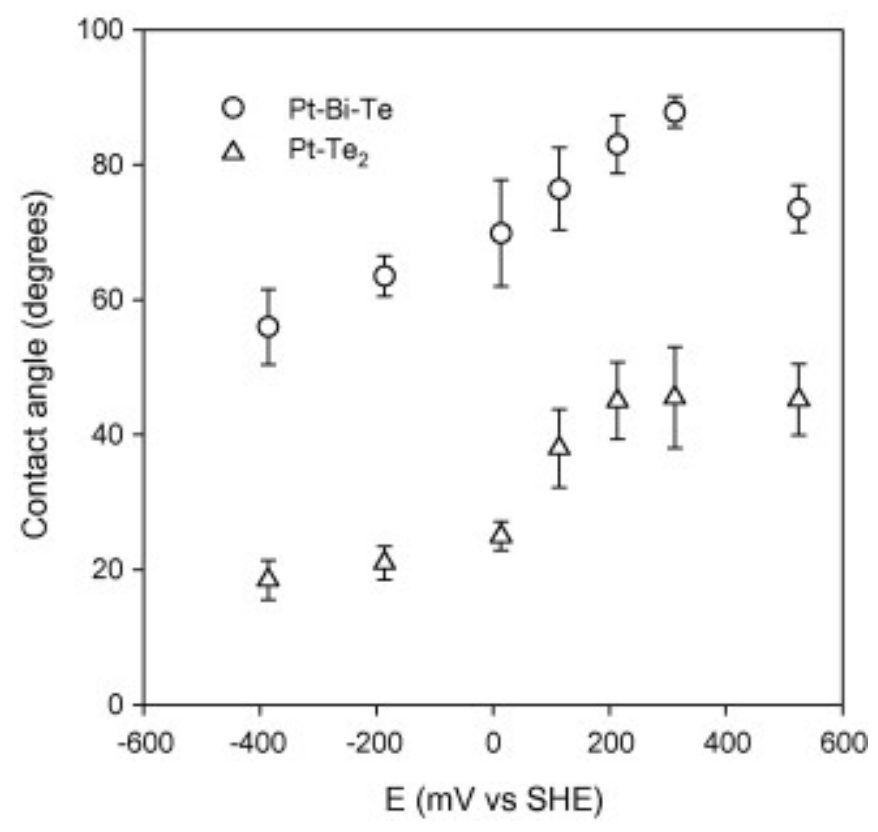

Fig. 11. Contact angles for Pt-Bi-Te and Pt-Te electrode in a $0.05 \mathrm{M} \mathrm{Na}_{2} \mathrm{~B}_{4} \mathrm{O}_{7}$ solution at $25{ }^{\circ} \mathrm{C}$ in the presence of $10^{-3} \mathrm{M}$ PAX after $300 \mathrm{~s}$ of polarisation at the relevant potential. 


\section{Conclusions}

The oxidation of ethyl xanthate on $\mathrm{Pt}-\mathrm{Te}_{2}$ and $\mathrm{Pt}-\mathrm{Bi}-\mathrm{Te}$ has been studied using electrochemically controlled contact angle measurements and electrochemical investigations. $\mathrm{Pt}-\mathrm{Bi}-\mathrm{Te}$ polarised in tetraborate indicated a cathodic peak that could be linked to the reduction of a species formed by the oxidation of bismuth. The polarisation diagrams of $\mathrm{Pt}-\mathrm{Bi}-\mathrm{Te}$ and $\mathrm{Pt}-\mathrm{Te}_{2}$ in tetraborate indicate the slightly more noble nature of the later for potentials $<300 \mathrm{mV}$. Pt-Te $\mathrm{T}_{2}$ and $\mathrm{Pt}-\mathrm{Bi}-\mathrm{Te}$ show anodic currents when polarised at $0.3 \mathrm{~V}(\mathrm{SHE})$ in a $0.05 \mathrm{M} \mathrm{Na}_{2} \mathrm{~B}_{4} \mathrm{O}_{7}$ solution containing $1 \times 10^{-3} \mathrm{M}$ potassium ethyl xanthate. The rest potential measurements of the two minerals in the presence of oxygen and xanthate indicate much higher open-circuit potential compared to the xanthate-dixanthogen equilibrium potential. Maximum contact angles of $63^{\circ}$ and $29^{\circ}$ were measured, respectively, on $\mathrm{Pt}-\mathrm{Bi}-\mathrm{Te}$ and $\mathrm{Pt}-\mathrm{Te}_{2}$. FT-IR spectroscopy has demonstrated that the anodic currents found on $\mathrm{Pt}-\mathrm{Bi}-\mathrm{Te}$ and $\mathrm{Pt}-\mathrm{Te}_{2}$ reflect the oxidation of xanthate to dixanthogen. The hydrophobic surface state of the $\mathrm{Pt}-\mathrm{Bi}-\mathrm{Te}$ will result in the flotation of the particle if sufficient quantities of the surfactant are present and successful bubble attachment is achieved. Surface roughness is a possible cause of the small contact angles measured on $\mathrm{Pt}-\mathrm{Te}_{2}$ despite the presence of dixanthogen.

\section{References}

Bozkurt et al., 1999 V. Bozkurt, Z. Xu, S.H.R. Brienne, I.S. Butler and J.A. Finch, In situ orientation study of xanthate on copper under potential control, Journal of Electroanalytical Chemistry 475 (1999), pp. 124-129.

Elvy et al., 1996 S.B. Elvy, P.A. Williams and A.N. Buckley, XPS evidence for the incongruent surface oxidation of minerals in the $\mathrm{Pd}-\mathrm{Te}-\mathrm{Bi}$ system, Surface and Interface Analysis 24 (1996), pp. 641-646.

Gardner and Woods, 1974 J.R. Gardner and R. Woods, An electrochemical investigation of contact angle and of flotation in the presence of alkylxanthates. I. Platinum and gold surfaces, Australian Journal of Chemistry 27 (1974), pp. 2139-2148. 
Leppinen et al., 1991 J.O. Leppinen, R.-H. Yoon and J.A. Mielczarski, FT-IR studies of ethyl xanthate adsorption on gold, silver and gold-silver alloys, Colloids and Surfaces 61 (1991), pp. 189-203.

Poling, 1976 G.W. Poling, Reactions between the thiol reagents and sulphide minerals. In: M.C. Feurstenau, Editor, Flotation: A.M. Gaudin Memorial Volume vol. 1, Port City Press, Inc., Baltimore (1976), pp. 334-363.

Pourbaix, 1974 M. Pourbaix, Atlas of electrochemical equilibria in aqueous solutions, National Association of Corrosion Engineers, Houston (1974).

Sundholm and Talonen, 1994 G. Sundholm and P. Talonen, Adsorption of ethyl xanthate anions on a silver electrode: an in-situ FTIR study, Journal of Electroanalytical chemistry 380 (1994), pp. 261-267.

Vermaak et al., 2004 M.K.G. Vermaak, J.A. Venter and P.C. Pistorius, Electrochemical studies of the interaction of ethyl xanthate with $\mathrm{Pd}-\mathrm{Bi}-\mathrm{Te}$, International Platinum Conference "Platinum Adding Value", South African Institute of Mining and Metallurgy, Johannesburg (2004) pp. 167-172.

Vermaak et al., 2005 M.K.G. Vermaak, P.C. Pistorius and J.A. Venter, Electrochemical and Raman spectroscopic studies of the interaction of ethyl xanthate with $\mathrm{Pd}-\mathrm{Bi}-\mathrm{Te}$, Minerals Engineering 18 (2005), pp. 575-584.

Yan and Hariyasa, 1997 D.S. Yan and Hariyasa, Selective flotation of pyrite and gold tellurides, Minerals Engineering 10 (3) (1997), pp. 327-337.

Corresponding author. Tel.: +27 12420 4208/84 587 5714; fax: +27 123625304 . 